\title{
У Työ- ja toimintakyvyn arviointimenetelmän kulttuurinen adaptointi kognitiivisen haastattelun menetelmällä: kokemuksia Kykyviisarin testauksesta arabian-, somalin, kurdin- ja venäjänkielillä
}

Tausta ja tavoitteet: Kulttuurinen ja kielellinen moninaisuus on kasvava osa suomalaista yhteiskuntaa. Arviointimenetelmien kulttuurisidonnaisuus voi rajoittaa toimintakyvyn arvioinnin luotettavuutta ja asettaa henkilöt eriarvoiseen asemaan asiakastilanteissa. Tämä artikkeli kuvaa prosessia, jolla arviointimenetelmää kehitettiin kognitiivisen haastattelun menetelmällä.

Menetelmät: Kulttuurisensitiiviset toimintakyvyn arviointimenetelmät mobiilissa (mobiTARM0) -hankkeessa kartoitettiin toimintakyvyn arviointimenetelmää, joka soveltuisi kotouttamistyöhön. Työ- ja toimintakyvyn arviointiin kehitetty Kykyviisari-menetelmä käännettiin arabiaksi, somaliksi sekä kurdiksi (sorani) ja venäjäksi. Menetelmän kulttuurisensitïvisyyttä tutkittiin kognitïivisella haastattelulla $(\mathrm{N}=6 \mathrm{I})$. Haastatteluaineisto analysoitiin sisältöanalyyttisin menetelmin.

Tulokset: Kognitiivinen haastattelu osoitti, että monet tekijät vaikuttavat käännösten ymmärrettävyyteen. Tietyt ilmiöt (esim. käsitys perheestä ja vapaa-ajasta) näyttäytyivät kulttuurisidonnaisina. Kyselyn ongelmakohdat painottuivat kielestä rïppumatta samoihin asioihin, ja siten kysymysten kulttuurinen adaptointi toteutettiin yhdenmukaisesti kaikille kielille.

Kykyviisarin kulttuurinen adaptointi toteutettiin a) tarkentamalla itse kysymystä ja hyödyntämällä käännettävän kysymyksen muotoilussa selkokielistä kysymyksen asettelua,

b) lisäämällä selitteitä vastausvaihtoehtoihin selkokielisen lomakkeen mukaisesti sekä c) lisäämällä kohderyhmälle räätälöityjä selitteitä.

Johtopäätökset: Kulttuurien välisestä kognitïivisesta haastattelusta oli selkeää hyötyä arviointimenetelmän kehittämisessä. Lopputuloksena on arabian-, somalin, kurdin- ja venäjänkielisille vastaajille soveltuvat versiot Kykyviisarista. Kulttuurisensitiivinen arviointi edellyttää kielellisesti ja kulttuurisesti sopivan arviointimenetelmän lisäksi myös arvostavaa vuorovaikutusta ja kohtaamista ammattilaisen ja asiakkaan välillä.

ASIASANAT: kognitiivinen haastattelu; kulttuurisensitiivisyys; kotouttaminen; maahanmuutto

MISHA HENRIKSSON, SHADIA RASK, HEIDI ANTTILA, MIIA WIKSTRÖM, MINNA SAVINAINEN, HANNAMARIA KUUSIO 


\section{YDINASIAT}

- Arviointimenetelmän kulttuurisidonnaisuus voi rajoittaa työ- ja toimintakyvyn arvioinnin luotettavuutta.

- Kognitiivisen haastattelun menetelmällä voi tutkia ja kehittää arviointimenetelmän soveltuvuutta ja kulttuurisensitiivisyyttä.
- Kysymysten tulkintoihin vaikuttavat paitsi kieleen ja kulttuuriin liittyvät seikat myös vastaajan tausta ja haastattelutilanne.

- Kykyviisarin kieliversioilla voi arvioida työ- ja toimintakykyä kotoutumisvaiheessa.

\section{JOHDANTO}

Työ- ja toimintakyvyn arviointia edellytetään lainsäädännössä erilaisten palveluiden ja etuuksien saamiseksi. Arvioinnin tulisi vahvistaa asiakkaan toimijuutta ja kykyä tunnistaa omia voimavaroja (Sainio \& Salminen 2016). Tämä edellyttää, että arviointi on yhdenvertaista ja luotettavaa, riippumatta asiakkaan kulttuurisesta tai kielellisestä taustasta. Suomeen muuttaneen ihmisen työ- ja toimintakykyä arvioidaan esimerkiksi kotoutumislaissa määritellyssä alkukartoituksessa, jossa selvitetään työllistymis-, opiskelu- ja muut kotoutumisvalmiudet sekä palvelujen tarve (Laki kotoutumisen edistämisestä 30.12.2010/1386). Haasteena on, että arviointimenetelmät ovat lähtökohtaisesti aina kulttuurisidonnaisia (Suomen Psykologiliitto 2018).

Kognitiivinen haastattelu on menetelmä, jossa mittarin tai kyselylomakkeen kehitystä tehdään yhdessä haastateltavan kanssa (Willis 2005; Anttila ym. 2017). Sen toteutustavat ovat moninaiset (Buers ym. 2014; Lee 2014; Willis \& Miller 2011; Willis 2005). Kognitiivisen haastattelun avulla voidaan testata itsearviointilomakkeita, mittareita tai muita haastattelukysymyksiä, tutkia näiden ymmärrettävyyttä ja havainnoida ongelmia kysymyksiin vastaamisessa (Park ym. 2013).

Pyrkimys kysymysten ymmärrettävyyteen ja selkeyteen palvelee sekä vastaajaa että tiedonkeruun laatua (Kotilainen 2014). Vaikeat kysymykset lisäävät väärinymmärrysten ja ei-toivottujen tulosten sekä vastaamatta jättämisen riskiä (ks. Unkila ym. 2018). Esimerkiksi kysyttäessä "pystytkö lukemaan tekstiä silmälasien kanssa tai ilman" haastateltava saattaa ymmärtää kysymyksen koskevan lukutaitoa eikä näkökykyä (Kotilainen 2013). Kognitiivinen haastattelu soveltuu kulttuuriseen adaptointiin, jossa kysymyksiä hiotaan eri lähtömaista ja -kulttuureista tuleville sopivaksi ilman, että niiden alkuperäi- nen merkitys muuttuu (Andreasen ym. 2014). Prosessi auttaa hahmottamaan, mitkä tekijät vaikuttavat vastaamiseen eri väestöryhmillä (Willis \& Miller 2011).

Tässä artikkelissa kuvataan prosessia, jolla työ- ja toimintakyvyn arviointimenetelmää kehitettiin kognitiivisen haastattelun menetelmällä. Tavoitteena oli tutkia, miten työ- ja toimintakyvyn arviointimenetelmää voidaan kulttuurisesti adaptoida kognitiivista haastattelua hyödyntäen.

\section{TUTKIMUSAINEISTO JA MENETELMÄ}

\section{ARVIOINTIMENETELMÄ}

Laajassa kartoituksessa tarkasteltiin yli 60 menetelmää tavoitteena löytää kotoutumisvaiheessa olevan asiakkaan toimintakyvyn ja palvelutarpeen arviointiin soveltuva työkalu. Arviointimenetelmäksi valikoitui Työterveyslaitoksen (TTL) kehittämä Kykyviisari. Se on työ- ja toimintakyvyn itsearviointimenetelmä, joka voidaan täyttää sähköisesti tai paperilomakkeella, yksin tai ammattilaisen kanssa (ks. Työterveyslaitos 2019). Kykyviisarin etuna oli aikaisempi kehitystyö (Unkila ym. 2018), hyvät kokemukset useissa hankkeissa, useat kieliversiot (suomi, ruotsi, englanti ja selkosuomi) sekä valmis sähköinen alusta ja raportointijärjestelmä. Rajoitteet olivat validointitutkimuksen puute, lomakkeen pituus erityisesti moniongelmaisille asiakkaille sekä puuttuvat osaalueet, kuten kipu- ja traumakokemukset.

Kykyviisari käännätettiin arabiaksi, somaliksi, kurdiksi (sorani) ja venäjäksi. Kieliversiot käännettiin takaisin suomenkielelle luotettavuuden varmistamiseksi.

\section{TUTKIMUSMENETELMÄ}

Kykyviisarin kulttuurisensitiivisiä ominaisuuksia tutkittiin kognitiivisen haastattelun menetelmällä. 
Tutkimuksessa arvioitiin, kuinka lomakkeen kysymykset ymmärrettiin, miten hyvin ne kartoittavat yksilön tilannetta ja voisiko kysymykset esittää toisin (mukaillen Anttila ym. 2017 \& Willis 2015). Tutkittava täytti ensiksi Kykyviisari-lomakkeen tai sen osion itsenäisesti tai haastatteluna. Tämän jälkeen tutkijat toteuttivat kognitiivisen haastattelun tulkin välityksellä. Havainnot koottiin yhteen ja sisällönanalyysillä arvioitiin toistuvia teemoja ja näiden suhdetta tutkittavaan ilmiöön (Tuomi \& Sarajärvi 2002). Analyysin pohjalta Kykyviisariin kieliversioille toteutettiin kulttuurinen adaptointi.

\section{TUTKIMUSAINEISTO}

Tutkimuksen haastateltavat kerättiin pääkaupunkiseudun kotoutumiskoulutusryhmistä sekä järjestöjen kautta. Osallistuminen oli vapaaehtoista ja tapahtui anonyymisti. Haastattelut toteutettiin joulukuun 2017 ja toukokuun 2019 välillä ja niiden pituus oli 45-60 minuuttia. Haastattelut toteutettiin pääosin yksilöhaastatteluina $(n=52)$. Lisäksi tehtiin neljä ryhmähaastattelua. Haastateltavista $(\mathrm{N}=61)$ sekä arabian- että somalinkielisiä oli 20, kurdinkielisiä 12 ja venäjänkielisiä 9 henkilöä. He olivat 20-68-ikävuoden väliltä, joista noin puolet naisia. Haastateltavat edustivat eri koulutustaustoja: mukana oli sekä luku- ja kirjoitustaidottomia että korkeasti koulutettuja.

Tutkimussuunnitelma kognitiivisten haastatteluille hyväksyttiin Terveyden ja hyvinvoinnin laitoksen tutkimuseettisessä työryhmässä (10.10.2017).

\section{TULOKSET}

Haastatteluissa havaittiin, että Kykyviisarin ongelmakohdat painottuivat kieliryhmästä riippumatta samoihin asioihin. Yksilö- ja ryhmähaastattelujen tulosten välillä ei ollut eroa. Kulttuurinen adaptointi toteutettiin yhdenmukaisesti kaikille kielille. Kykyviisarin 84 kysymyksestä 22:ta räätälöitiin tarkentamalla itse kysymystä esimerkiksi hyödyntämällä selkokielistä kysymyksen asettelua; neljää lisäämällä selitteitä vastausvaihtoehtoihin selkokielisen lomakkeen mukaisesti; ja 11:ta lisäämällä kohderyhmälle räätälöityjä selitteitä kysymyksiin. Lisäksi selkeytettiin ja täydennettiin vastausasteikkoja sekä otsikoita. Seuraavassa kuvataan osiokohtaiset havainnot.

\section{ESITIEDOT}

Kykyviisarin aluksi kysytään vastaajan ikä ja sukupuoli. Ikä pyydetään kirjaamaan vuosina, mutta muutamalle vastaajalle oli epäselvää, tarkoitetaanko tässä ikää vai syntymävuotta.

\section{HYVINVOINTI}

Hyvinvointi-osiossa arvioidaan nykyistä terveydentilaa sekä tyytyväisyyttä elämään vastaushetkellä. Monelle jäi epäselväksi, tarkoitetaanko näillä tilannetta Suomessa vai entisessä kotimaassa. Sekä toiminta- ja työkykyä että suhdetta työelämään kartoittaviin kysymyksiin vastataan 0-10-asteikolla. Osa koki hankalaksi sijoittaa itsensä asteikolle, ja he olisivat ennemmin sanoittaneet kokemuksensa.

\section{OSALLISUUS}

Osallisuus-osiossa on 12 väittämää, joita arvioidaan viisiportaisesti (täysin eri mieltä - täysin samaa mieltä) sekä viisi yksittäistä kysymystä (esim. yksinäisyys).

Epäselvyyttä oli erityisesti kysymyksissä, joissa tekeminen tai sen kohde ei ollut konkreettisesti ilmaistu. Esimerkiksi väittämä "Saan apua, kun sitä tarvitsen" koettiin epäselväksi kahdesta syystä: 1) mitä apua väittämässä tarkoitetaan ja 2) kuka on avun antaja. Vastaamista hankaloitti myös, jos vastaaja ei tiennyt koskiko kysymys tilannetta Suomessa vai aiemmassa kotimaassa.

Osassa haastatteluista kävi ilmi, että abstrakti tunneperäinen kokemus yksinäisyydestä ("Tunnetko itsesi yksinäiseksi") ymmärrettiin tarkoittavan yksinoloa tai yksinasumista. Myös kysymys harrastuksista tuotti tulkintaeroja. Erityisesti somaliksi ja kurdiksi harrastus-sanalle ei löytynyt suoraa helposti ymmärrettävää vastinetta. Käännöksestä riippuen harrastus-sanan ymmärrettiin tarkoittavan pelkästään liikuntaa.

\section{MIELI}

Mieli-osio koostuu yhdeksästä väittämästä, joihin vastataan viisiportaisella asteikolla (ei koskaan - koko ajan). Haastatteluissa nousi esiin tulkintaeroja konkreettisesta abstraktiin. Väittämä "Olen tuntenut itseni rauhalliseksi" tulkittiin usein vihaisuuden vastakohtana. Vastaavasti "Olen tuntenut läheisyyttä toisiin ihmisiin" saattoi toiselle tarkoittaa globaalia solidaarisuutta, toiselle fyysistä läheisyyttä vieressä istuvan haastattelijaan. 
Haastateltavat kertoivat kysymysten lomassa hyvinkin avoimesti elämäntilanteistaan ja terveysongelmistaan. Näistä kertomuksista huolimatta haastateltavat vastasivat Mieli-osion kysymyksiin lähes poikkeuksetta myönteisesti. Tämä kyseenalaisti osion erottelevuuden. Lomakkeen kysymysten ulkopuolelle jäi tärkeitä aiheita, kuten ahdistusoireet.

\section{ARKI}

Arki-osiossa vastaajaa pyydetään arvioimaan suoriutumistaan viisiportaisesti (en suoriudu - suoriudun hyvin). Monet pitivät osion kysymyksistä, koska niissä käytiin läpi arkeen vaikuttavia asioita. Haastateltavista muutama koki selviävänsä arjesta jonkun muun avulla (esim. puoliso tai ystävä), mutta tämä ei ollut vastausvaihtoehtona.

Väitteissä annetut esimerkit pääsääntöisesti helpottivat vastaamista, mutta poikkeuksiakin oli. Esimerkiksi terveyspalvelujen kohdalla täsmennys "esim. lääkärissä käynti, hammashuolto, laboratorio" tuotti vaikeuksia, koska näissä käynti koettiin helpoksi, mutta ajanvaraaminen ei. Julkisten palvelujen käyttöön liittyen esimerkit (pankki, KELA, apteekki, TE-toimisto, sosiaalitoimisto) ei aina koettu yhteismitallisiksi, koska kaikissa ei voinut asioida omalla kielellä. Vastaavasti Internetin kautta asioimisen ja tiedonhaun esimerkkien (verkkopankki, lomakkeiden täyttö, aikataulu) kohdalla osa kuvasi osaavansa käyttää verkkopankkia ja reittiopasta, mutta lomakkeiden täytön olevan mahdotonta.

\section{TAIDOT}

Taidot-osiossa arvioidaan keskittymistä, oppimista ja muistia viisiportaisella asteikolla (erittäin hyvin - erittäin huonosti). Lisäksi on kysymys todetuista oppimisvaikeuksista sekä kuusi väittämää, joissa vastaaja arvioi tulevaisuuttaan viisiportaisesti (täysin eri mieltä - täysin samaa mieltä).

Monet kuvasivat kysymysten aiheita tärkeiksi ja relevanteiksi, mutta joihinkin kysymyksiin liittyi tulkintavaikeuksia. Erityisen vaikeaksi koettiin kysymys todetuista oppimisvaikeuksista. Useat toivoivatkin, että kysymyksessä tuotaisiin tarkemmin esiin, kuka on todennut ne (esim. lääkäri, opettaja tai muu). Taito-osion vastauksiin vaikutti myös, tulkittiinko niiden koskevan suomen- vai vastaajan äidinkieltä.

\section{KEHO}

Keho-osiossa arvioidaan fyysistä kuntoa (viisiportaisesti hyvä-huono), liikunnan määrää, apuvälineen käyttöä ja fyysistä toimintakykyä. Osiossa kysytään myös pitkäaikaissairauksista (kylläei) sekä pitkäaikaissairauden aiheuttamasta haitasta. Osio vaikutti pääosin selkeältä, mutta kysymys pitkäaikaisista sairauksista koettiin toistuvasti hankalana ja siihen vastaaminen vei monilta aikaa. Tätä voi selittää se, että vastaajalla saattoi olla useita erinäisiä sairauksia.

\section{TAUSTATIEDOT}

Taustatiedot-osio käsittelee kotitalouden tilannetta, tuloja ja koulutustaustaa. Osiossa oli joitain kysymyksiä, joihin vastaaminen oli hankalaa ja haastateltavien vastaukset olivat ristiriidassa aiemmin kerrotun kanssa. Tällaisia olivat muun muassa kysymys kotitalouden tilanteesta sekä koulutustaustasta. Esimerkiksi useampi yliopistossa opiskellut haastateltava halusi jättää kysymyksen peruskoulutuksesta tyhjäksi painottaen, että on opiskellut pidemmälle.

Myös osa termeistä hankaloitti vastaamista. Esimerkiksi kysymys avo- tai avioliitosta oli joillekin outo ja siihen jätettiin vastaamatta, koska avoliitto saatettiin kokea tabuna. Myös käsitteet yksinhuoltajuus ja yhteishuoltajuus olivat vaikeasti käännettävissä ja ymmärrettävissä. Yksi haastateltava kertoi asuvansa yksin lapsensa kanssa, ja valitsi tällä perusteella vaihtoehdon "asun yksin". Jotkin vastausvaihtoehdot koettiin muistuttavan kovasti toisiaan, kuten "asun ryhmäkodissa tai laitoksessa", "asun vastaanottokeskuksessa" tai "asun asumispalveluyksikössä".

\section{TYÖ JA TULEVAISUUS}

Lomakkeen viimeisessä osiossa kysytään nykyistä työtilannetta sekä mahdollisen työttömyyden kestoa. Näitä seuraa yhdeksän kysymyksen patteri, jossa kartoitetaan työelämään osallistumista vaikeuttavia tekijöitä. Lopuksi kysytään arviota työpaikan ja koulutuspaikan löytymisen todennäköisyydestä sekä muutosta vaativista elämän osa-alueista.

Jotkin suomalaista yhteiskuntaa koskevat sanat olivat vaikeasti käännettäviä tai muuten vieraita haastateltaville. Esimerkiksi sana luottotiedot oli käännetty luottamuksen menetykseksi. Toinen esimerkki oli oppisopimuskoulutus, jolle ei siksi löytynyt suoraa käännöstä. Lisäksi useille 
vastaajille oli epäselvää, mitä eroa on olla työttömänä työn työnhakijana TE-toimistossa tai pelkästään työttömänä.

\section{POHDINTA}

Kognitiivinen haastattelu osoitti, että Kykyviisarin kysymysten tulkintoihin vaikuttivat kieli- ja kulttuurikysymykset, käännösten sanavalinnat sekä haastateltavan tilanne. Vaikka käännösprosessissa toteutettiin takaisinkäännökset ennen kognitiivisten haastatteluiden aloittamista, käännösten laatua ei voitu täydellisesti testata ennen haastatteluita. Haastatteluista ilmeni varsin nopeasti kohdat, jotka eivät vastanneet alkuperäistä merkitystään. Usein ongelmana ei ollut käännösten laatu tai täsmällisyys. Päinvastoin täsmällisyys johti tilanteisiin, joissa asiayhteys unohtui.

Kognitiivinen haastattelu oli osalle haastateltavista alkuun hämmentävä: vastaajat eivät olleet tottuneet, että viranomaistilanteissa kysyttäisiin heidän mielipidettään. Esimerkiksi kognitiivisen haastattelun kysymys "mitä tämä termi tarkoittaa sinulle", saatettiin ymmärtää testinä, johon vastaaja oletti sisältyvän oikea vastaus (ks. Park ym. 2013). Vastaajien rohkeus ja motivaatio mielipiteen ilmaisuun kasvoi haastattelun edetessä.

Ammattitaitoisen tulkin käyttäminen oli edellytys kulttuurien välisen kognitiivisen haastattelun onnistumiselle. Toisaalta tulkki saattoi omaaloitteisesti selventää kysymyksiä haastateltavalle, mikä ei palvellut tutkimusta (ks. Chan \& Pan 2011). Lisäksi tulkin ollessa paikalla haastateltavat herkästi kääntyivät hänen puoleensa, jos eivät ymmärtäneet kysymystä tai empivät vastaustaan.

Menetelmän haaste on, että sillä ei ole yhtenevää toteutustapaa (Buers ym. 2014; Lee 2014), mistä johtuen aineiston analyysi ei ole välttämättä yhteneväistä tai systemaattista (Ridolfo \& Schoua-Glusberg 2011). Havaintojen systemaattinen kirjaaminen olikin yksi haastavimmista osuuksista haastatteluissa. Kognitiivista menetelmää on myös kritisoitu siitä, että havainnoissa keskitytään usein kysymyslomakkeiden ongelmakohtiin, jolloin toimivat ja hyvät kysymykset jäävät huomioimatta (emt.).

Tuloksia analysoidessa on varottava kulttuurisia ylitulkintoja. Kulttuuristen tekijöiden ohella myös vastaajien yhteiskunnallinen ja sosiaalinen asema vaikuttavat kysymysten tulkintaan (Ridolfo \& Schoua-Glusberg 2011). Vastaukset ovat myös riippuvaisia tilanteen pohjustamisesta (priming), jossa ulkoiset tekijät kuten kieli tai kulttuuri sekä annetut tekijät, kuten yhteisöllisyyden korostaminen tai lomakkeen rakenne voivat vaikuttaa vastauksiin (Schwarz ym. 2010 ja Oyserman \& Lee 2008). Kognitiiviset haastattelut toteutettiin kotoutumiskoulutuksessa; on selvää, että tällä kontekstilla oli vaikutusta kysymysten tulkintaan.

Tässä artikkelissa esitettyjen näkökulmien ulkopuolelle jää lukuisia syitä, minkä takia kysymykset saatetaan ymmärtää eri tavalla. Kulttuuriset erot eivät ole pelkästään lähtömaa- tai kielikysymyksiä, vaan syyt tulkintaerojen taustalla voivat piillä muualla. Näiden syvällisempi ymmärtäminen vaatisi lisää tutkimusta.

\section{JOHTOPÄÄTÖKSET}

Kognitiivinen haastattelu tarjoaa tavan testata ja kehittää kulttuurisensitiivisiä työ- ja toimintakyvyn arviointimenetelmiä. Menetelmä antaa erityisellä tavalla äänen kyselylomakkeen varsinaisille käyttäjille. Kykyviisarin käännetyillä ja räätälöidyillä kieliversioilla voi arvioida työ- ja toimintakykyä kotoutumisvaiheessa. Kulttuurisensitiivinen arviointi edellyttää aina paitsi kielellisesti ja kulttuurisesti sopivaa arviointimenetelmää, myös arvostavaa vuorovaikutusta ja kohtaamista.

\section{KIITOKSET:}

Kiitämme tutkimuksen osallistujia sekä Arffman Consulting Oy:ta ja FARO:a yhteistyöstä.

\section{RAHOITTAJAT:}

mobiTARMO-hanketta rahoitti Euroopan unionin turvapaikka- ja maahanmuuttorahasto (AMIF). Sosiaalisen osallisuus ja työ- ja toimintakyvyn muutos (Solmu) -koordinaatiohankkeen rahoittaja on Euroopan sosiaalirahasto (ESR).

\section{KIRJOITTAJIEN KONTRIBUUTIOT:}

Henriksson, Rask, Anttila ja Kuusio osallistuivat tutkimuksen suunnitteluun. Wikström ja Savinainen vastasivat Kykyviisarin kehittämistyöstä. Rask ja Henriksson toteuttivat aineiston keruun ja analysoinnin. Henriksson kirjoitti ensimmäisen käsikirjoituksen. Rask, Anttila, Wikström, Savinainen ja Kuusio kommentoivat käsikirjoitusta. Henriksson, Rask, Anttila, Wikström, Savinainen ja Kuusio hyväksyivät käsikirjoituksen. 
Background and aim: Cultural and linguistic diversity is a growing part of Finnish society. This needs to be taken into account in cross-cultural assessment of functioning to ensure equal and reliable outcomes. This article describes a process through which an assessment tool was developed using cross-cultural cognitive interviews.

Method: The Culturally sensitive functioning measures in a mobile application (mobiTARMO) -project mapped suitable evaluation tools for integration settings. The Abilitator, a method for self-assessment of work ability and functioning, was translated into Arabic, Somali, Kurdish (Sorani) and Russian. The cultural sensitivity of the Abilitator was tested with cognitive interviews $(\mathrm{N}=61)$. The data was analyzed using content analysis.

Results: Cognitive interviews showed that various factors affect the quality and understandability of the translations. Some aspects, such as views of family or free-time, were more bound by culture. The challenges in the questionnaire were consistent regardless of the language of the translation, and thus the cultural adaptation of the questions was conducted uniformly in all languages.

The cultural adaptation of the Abilitator was conducted in three ways: a) the question itself was made clearer, often utilizing the simple language form, b) by adding more definitions to answer options, and c) by adding examples and details designed for the target group.

Conclusions: Cross-cultural cognitive interview was clearly beneficial for the development of a culturally sensitive evaluation tool. The end results are adapted versions of the Abilitator suitable for Arabic, Somali, Kurdish and Russian speaking respondents. Culturally sensitive evaluation requires suitable tools, as well as open and respectful interaction between the professional and the individual.

Keywords: cognitive interview; cultural sensitivity; integration; immigration

$$
\begin{array}{cr}
\text { Saapunut } & 22.08 .2019 \\
\text { Hyväksytty } & 22.09 .2019
\end{array}
$$

\section{LÄHTEET}

(1) Andreasen J ym. Danish version of the Tilburg Frailty Indicator - Translation, cross-cultural adaptation and validity pretest by cognitive interviewing. Archives of Gerontology and Geriatrics 2014;59(1):32-38. doi: 10.1016/j.archger.2014.02.007

(2) Anttila H, Kokko K, Valkeinen H, Hiekkala S. PROMIS fyysinen toimintakyky - mittarin kääntäminen ja kulttuurinen adaptointi. Fysioterapia. 2017;3:33-35. http://urn.fi/URN:NBN:fi-fe201705036299

(3) Buers $C$ ym. The value of cognitive interviewing for optimizing a patient experience survey. International Journal of Social Research Methodology 2014;17(4):325-340. doi: 10.1080/13645579.2012.750830

(4) Chan AY, Pan Y. The Use of Cognitive Interviewing to Explore the Effectiveness of Advance Supplemental Materials among Five Language Groups. Field Methods 2011;23(4):342-361. doi: $10.1177 / 1525822 \times 11414836$

(5) Kotilainen A. Ulkomailla syntyneiden terveys ja hyvinvointi -lomake: neljän kysymyksen

testaus. Lomaketestaukset-sarja.2013:6/13. Tilastokeskus.

(6) Kotilainen A. Lomakkeen selkokielisyys parantaa tiedonkeruun laatua. Hyvinvointikatsaus. 2014;3.

(7) Laki kotoutumisen edistämisestä 30.12.2010/1386. https://www.finlex.fi/fi/laki/ ajantasa/2010/20101386

(8) Lee J. Conducting Cognitive Interviews in CrossNational Settings. Assessment 2014;21(2):227240. doi: 10.1037/e503712013-001

(9) Oyserman D, Lee SW. Does culture influence what and how we think? Effects of priming individualism and collectivism. Psychol Bull 2008 Mar;134(2):311-342.

doi: 10.1037/0033-2909.134.2.311

(10) Park H, Sha MM, Pan Y. Investigating validity and effectiveness of cognitive interviewing as a pretesting method for non-English questionnaires: Findings from Korean cognitive interviews. International Journal of Social Research Methodology 2014;17(6):643-658. doi: 10.1080/13645579.2013.823002 
(11) Ridolfo H, Schoua-Glusberg A. Analyzing Cognitive Interview Data Using the Constant Comparative Method of Analysis to Understand Cross-Cultural Patterns in Survey Data. Field Methods 2011;23(4):420-438. doi: $10.1177 / 1525822 \times 11414835$

(12) Sainio P ja Salminen A-L. Toimintakyvyn arviointi ja menetelmät. Kirjassa Autti-Rämö I, Salminen A-L, Rajavaara M ja Ylinen A (toim.). Kuntoutuminen. Duodecim. 2016, 206-224

(13) Schwarz N, Oyserman D, Peytcheva E. Cognition, communication, and culture: Implications for the survey response process. Hoboken, NJ, US: John Wiley \& Sons Inc; 2010. p. $177-190$. doi: 10.1002/9780470609927.ch10

(14) Suomen Psykologiliitto 2018. Monikulttuurisuus ja psykologinen arviointi. Suomen Psykologiliitto ry:n ja Suomen psykologinen seura ry:n asettama Testilautakunta. Päivitetty 24.4.2018. https:// www.psyli.fi/files/4113/Testilautakunnan ohje_Monikulttuurisuus_ja_psykologinen_ arviointi_2018.pdf

(15) Tuomi J. \& Sarajärvi A. Laadullinen tutkimus ja sisällönanalyysi. Helsinki: Tammi. 2002. Työterveyslaitos 2019. Kykyviisari. Työ- ja toimintakyvyn itsearviointimenetelmä. Käyttöopas.

(16) Willis GB. Cognitive interviewing: a tool for improving questionnaire design. Thousand Oaks (Calif.): Sage; 2005.

(17) Willis GB, Miller K. Cross-Cultural Cognitive Interviewing: Seeking Comparability and Enhancing Understanding. Field Methods 2011;23(4):331-341. doi: $10.1177 / 1525822 \times 11416092$

(18) Willis GB. The Practice of Cross-Cultural Cognitive Interviewing. Public Opinion Quarterly 2015;79(S1):359-395. doi: $10.1093 / \mathrm{poq} / \mathrm{nfu} 092$
(19) Unkila K ym. 2018. Kognitiivinen haastattelu kyselylomakkeen kehittämisessä. Esimerkkinä työ- ja toimintakyvyn itsearviointimenetelmä Kykyviisari. Kuntoutus 1/2018 ss. 17-24.

\author{
Misha HenRiksson \\ YTM, projektisuunnittelija \\ Terveyden ja hyvinvoinnin laitos \\ Hyvinvointiosasto \\ Yhdenvertaisuus ja osallisuus -yksikkö
}

SHADIA RASK

FT, tutkimuspäällikkö

Terveyden ja hyvinvoinnin laitos

Hyvinvointiosasto

Yhdenvertaisuus ja osallisuus -yksikkö

\section{Heidi AnTtila}

FT, erikoistutkija

Terveyden ja hyvinvoinnin laitos

Hyvinvointiosasto

Yhdenvertaisuus ja osallisuus -yksikkö

\author{
MiıA Wikström \\ LitM, tutkija, hankejohtaja \\ Työterveyslaitos \\ Työkyky ja työurat
}

\begin{abstract}
Minna Savinainen
$T t T$, tft, erikoistutkija

Työterveyslaitos
\end{abstract}

HANNAMARIA KuUSIO
FT, tutkimuspäällikkö
Terveyden ja hyvinvoinnin laitos
Hyvinvointiosasto
Yhdenvertaisuus ja osallisuus -yksikkö

